\title{
Leonardo, a flauta: uns sentimentos selvagens ${ }^{1}$
}

\author{
Rafael José de Menezes Bastos ${ }^{2}$ \\ Professor do Departamento de Antropologia - UFSC
}

RESUMO: Este artigo pretende contribuir para a etnologia das "flautas sagradas" nas Terras Baixas da América do Sul, retomando a análise de um episódio ocorrido entre 1947 e 1953, envolvendo Leonardo Villas Boas e os índios kamayurá, xinguanos tupi-guarani. Nesse momento, Leonardo manteve, continuada e publicamente, relaçōes amorosas com Pele de Reclusa, esposa do grande xamã e chefe Kutamapù. $\mathrm{O}$ affair provocou comoção entre os índios, que colocaram um trio de flautas na casa do herói. Assim, quando Pele de Reclusa a freqüentava, via as flautas. Violada a regra que proíbe às mulheres ver as flautas, Pele de Reclusa sofreu estupro coletivo, o que originou seu ostracismo e o afastamento dos Villas Boas dos Kamayurá. Para estes, "ver" contrasta com "ouvir". A primeira noção aponta para uma forma analítica de conhecimento ("explicação"), a segunda, sintética ("compreensão"). A exacerbação da capacidade de "ver" é, para eles, sinal de associalidade - no caso dos feiticeiros - e de suprema socialidade - no caso dos pajés. O exagero da aptidão de "ouvir", ao contrário, é considerado condição de virtuosidade na música e nas artes verbais. Se entre esses índios, às mulheres é vedado ver as flautas, ouvi-las é delas esperado. As pistas para a compreensão indígena do episódio provêm de sua maneira de construção dos sentidos, dos gêneros e do poder - no todo, de sua forma de constituição do mundo: quando Pele de Reclusa violou o inviolável, Leonardo transformou-se em "flauta", sua casa na "casa das flautas", e os homens numa coletividade delas, tudo passando a ocorrer sob sua ética feroz.

PALAVRAS-CHAVE: flautas sagradas, Alto Xingu, índios kamayurá, cosmologia, audição do mundo. 
The other great branch of sympathetic magic, which I have called Contagious Magic, proceeds upon the notion that things which have once been conjoined must remain ever afterwards, even when quite dissevered from each other, in such a sympathetic relation that whatever is done to the one must similarly affect the other. Thus the logical basis of Contagious Magic, like that of Homoeopathic Magic, is a mistaken association of ideas; its physical basis, if we may speak of such a thing, like the physical basis of Homoeopathic Magic, is a material medium of some sort which, like the ether of modern physics, is assumed to unite distant objects and to convey impressions from one to the other. Sir James George Frazer (1854-1941), The Golden Bough (1922)

De que estamos falando ao usar a expressão "flautas sagradas" (ou "rituais”)? Responder a essa pergunta não é nada fácil. Tudo começa pelo fato de sabermos muito bem que não estamos a tratar simplesmente de "flautas". Ou melhor, dos aerofones tipologicamente identificados pelo número 421 no sistema de Hornbostel-Sachs (Hornbostel \& Sachs, 1961[1914]), um sistema de classificação de instrumentos musicais, aliás, que a grande maioria dos antropólogos e etnomusicólogos - os museólogos são excepcionais a esse respeito - nunca levou muito a sério, apesar - é o que acho - de seu grande interesse. ${ }^{4}$ Não tratamos somente de flautas, pois as "flautas sagradas", dependendo de cada caso etnográfico, podem compreender aerofones de vários tipos ou mesmo, como no caso xinguano (kamayurá) aqui abordado, além de várias espécies de aerofones ("flautas", "trompetes”, “clarinetes”, "zunidores”), várias categorias de idiofones 5 (chocalhos globulares, em fieira etc.). Mas não é somente devido a questões organológicas - de interesse sempre estra- 
Revista de Antropologia, São Paulo, USP, 2006, v. 49 no 2.

tégico para a compreensão do pensamento e da sensibilidade, tanto indígenas quanto daqueles que buscam conhecê-los - que a pergunta posta acima não é nada fácil de responder: pesa sobre a expressão em tela os qualificativos "sagradas" ou "rituais", às vezes substituídos por "secretas" ou outros, muito pouco adequados para descrever o estatuto dos instrumentos em consideração. ${ }^{6}$

Minha contribuição à abordagem da questão das flautas em consideração - que me mobiliza desde o começo de minhas pesquisas no Alto Xingu (ver Menezes Bastos, 1978[1999a]) - vai se dar por meio do breve estudo de um episódio envolvendo essas flautas, os índios kamayurá e os célebres irmãos Villas Boas. Num texto já antigo (Menezes Bastos, 1989), em que estudei as exegeses kamayurá (xinguanos tupi-guarani) e yawalapití (idem, aruaque) sobre o Parque Indígena do Xingu e a construção da saga dos citados heróis, recolhi uma narrativa que inclui a narração desse episódio. Cada vez mais descubro que ele tem um grande interesse para a compreensão do universo das "flautas sagradas" nas Terras Baixas da América do Sul, assim como do pensamento ameríndio em geral. Recordo que no texto referido cobri apenas com uma pequena nota de pé de página o episódio, passando, desde então, alguma parte dos cerca de 18 anos seguintes pensando nele. Resumirei aqui o que pensei, então.

A narrativa que conta o episódio, feita em 1981 por Takumã, então chefe kamayurá, reporta-se à época da chegada dos Villas Boas à região dos formadores do Rio Xingu. Isso coloca seu presente histórico mais ou menos entre os dois ou três últimos anos da década de 1940 e os dois ou três primeiros da de 1950 - algo como o intervalo 1947-1953. Takumã então era adolescente e estava no período de reclusão pubertária (hoje ele deve estar perto dos 80 anos). Conforme disse em meu texto de 1989, a narrativa revela uma face no mínimo descontente dos índios xinguanos - dos Kamayurá em particular - com os irmãos Villas Boas, 
intencionalmente buscando demolir a retórica assexuada por meio da qual sua saga sempre tentou se apresentar ao mundo. ${ }^{7}$ Pretendo, através da breve análise do episódio em tela - que apresenta as "flautas sagradas", por assim dizer, em ação, como agentes portanto -, contribuir para a etnologia das Terras Baixas da América do Sul nos capítulos referentes às maneiras ali vigentes de construção dos sentidos, dos gêneros e do poder - no todo, no capítulo relativo às formas ameríndias de constituição do mundo. Subsidiariamente, farei uma pequena excursão às temáticas do pensamento e do sentimento selvagens, rapidamente explorando a questão da construção ameríndia do mito e da história.

Transcrevo abaixo a narrativa em comentário, que dividi em cinco partes, numeradas de 1 a $5:^{8}$

1. [...] Aí eu fiquei no Xingu, ${ }^{9}$ com Leonardo. ${ }^{10}$ Fiquei. Fiquei por muito tempo ("dez anos"). Então meu pai me chamou de volta à aldeia. ${ }^{11}$ Lá, fui preso (reclusão pubertária). Fiquei preso por muito pouco tempo ("dois meses") e então fui embora de novo para o Xingu. ${ }^{12}$ Leonardo havia me chamado. Fiquei lá... Aí meu pai me chamou de novo. Em seguida, Leonardo foi buscar-me uma vez mais. Aí, eu fiquei, fiquei... com Leonardo. Nessa época, Leonardo me emprestou carabina. Depois, ele deu outra pra mim, uma 44. Aí, eu fiquei com ele, fiquei, fiquei...

2. Foi então, depois, que Leonardo errou o caminho. Ele namorou (algumas) índias. Ele tinha ciúme do pessoal (dos outros caraíbas): ${ }^{13}$ "Pessoal não pode namorar índias. Eles passam doenças para elas". Leonardo falava assim. Orlando também. Leonardo ficava brabo com o pessoal caraíba. Ele queria mandar todos os caraíbas embora. Mas, como? Os Villas Boas ficariam sozinhos. Aí, Leonardo me chamou: "Takumã, você tem que dizer para as mulheres não entrarem nas casas dos trabalhadores. Assim, eles vão passar doenças pra elas". Aí, eu fui falar com as mulheres. Elas me disseram: "Não, nós não temos ido às casas dos caraíbas, não". Aí, eu fi- 
quei conversando [com as mulheres kamayurá], conversando, conversando... Foi aí que Leonardo errou o caminho. ${ }^{14}$ Eu vi Leonardo errar o caminho. Os outros viram. Todo mundo viu...

3. Ele namorou Pele de Reclusa. Mulher de meu pai. Meu pai era casado com Pele de Reclusa. Ela era manga'uhet. ${ }^{15}$

4. Então, Pele de Reclusa viu yumiama’e (as flautas sagradas). ${ }^{16}$ Lá na casa de Leonardo nós havíamos deixado um trio de yumi ama’e. Pele de Reclusa, quando foi namorar com Leonardo, entrou lá, então viu as flautas. Então, o pessoal (os Kamayurá): "Vamos estuprar Pele de Reclusa”. Meu pai estava muito brabo. Meu pai sabia que Leonardo estava namorando Pele de Reclusa.

5. Aí, outro dia, nós tocamos as flautas. Pele de Reclusa estava na casa de Leonardo. Os dois estavam dentro de uma rede, com mosquiteiro. Pele de Reclusa estava no mosquiteiro. Ninguém sabia disso. Então, o pessoal tocou as flautas yumiama'e. Aí, Leonardo achou ruim: "Por que vocês tocaram isso?". Ele brigou com os Kamayurá. Falou mal, falou, falou... ${ }^{17}$ Então, Leonardo pegou um revólver e disse: "eu vou matar você, Takumã". Eu disse pra ele: "Pode matar". Ele apontou o revólver para minha cara. Meu pai disse: "Pode matar... Quem mata meu filho, pode me matar também... Por que você tem ciúme de seu pessoal?... Você está errado, Leonardo... Eu não quero mais Pele de Reclusa... Pode casar com ela...”.

De começo, o que eu gostaria de reter dessa narrativa impressionante é a dupla identificação - por contaminação - produzida no evento:

1) entre a "casa das flautas" (tapìy em kamayurá) e a casa de Leonardo; 2) e entre as flautas e o próprio herói. 
Essa identificação - e por isso a estou chamando de contaminação, num movimento que procura evocar $O$ ramo de ouro (aí estando, portanto, o nexo da epígrafe com o presente texto) - não se congela na pura equação mental, metonímica no caso, já que foi feita um fato do mundo empírico: a colocação das flautas no interior da casa de Leonardo transformou esta última na "casa das flautas", a partir de então tudo vindo a se passar - para Pele de Reclusa e Leonardo, ou de seus pontos de vista ou perspectivas (apesar de, por assim dizer, forçados) - como se Leonardo, ele mesmo, fosse um indivíduo da espécie yaku'i.

Observe-se que essa colocação foi feita intencionalmente, e tudo indica que a mando de Kutamapù, que, sabedor do affair entre Leonardo e Pele de Reclusa - continuado, público e caracterizado pelo exclusivismo, dir-se-ia pela "fidelidade", no caso da mulher em relação ao homem -, se sentiu vítima nada mais nada menos que de um ato de guerra do herói, do clássico tipo do roubo de mulheres. Kutamapù era, além de um grande chefe, um grande paye, "xamâ".

Produzida a identificação, a vingança feroz, o estupro de Pele de Reclusa pelos homens da aldeia - transformados numa comunidade de yaku'i-, pôde colocar-se no horizonte: Pele de Reclusa, ao freqüentar a casa de Leonardo, sem saber e querer, estava a freqüentar o tapùy ("casa das flautas"), espaço absolutamente interdito às mulheres entre os Kamayurá e xinguanos em geral, exatamente por ser a casa das yaku'i. Pior que isso, ao freqüentar aquela casa, Pele de Reclusa cotidianamente via as próprias flautas sagradas.

O segundo ponto que apreciaria reter do episódio formidando é cumulativo em relação ao primeiro: trata-se da colagem - também realizada para além de uma pura operação intelectual - que ele produziu entre Leonardo e 
Revista de Antropologia, São Paulo, USP, 2006, v. 49 no 2.

1) o ciúme (comportamento acumulador, no caso de mulheres);

2) a falta de discrição (ao manter, ele, relações sexuais bandeirosas com uma mulher casada, e - pior, pior - com uma das mulheres do chefe);

3) e a violência - verbal ("falar mal", "xingar") e física (expressa por meio da ameaça de morte com revólver) -, dirigida, centralmente, nada mais nada menos que a Takumã, filho do chefe kamayurá e primeiro na linha de sua sucessão. Essa violência se evidenciou de maneira ainda mais cabal para os Kamayurá pelo fato de Leonardo - tornado uma flauta, ou um indivíduo da espécie yaku’i - ter reclamado (na quinta e última parte da narrativa) de maneira raivosa de sua execução em sua casa (transformada, como se viu, em "casa das flautas") - a flauta reclamava, com raiva, da execução de sua própria música. Recordo que essa reclamação veio a culminar na ameaça de Leonardo a Takumã, com revólver em punho.

Essa colagem dá o arremate final à identificação produzida pelos Kamayurá de Leonardo Villas Boas: ela se evidencia no patamar não simplesmente de um feiticeiro, alguém que enfim pode ter seu poder associal eliminado pela sociedade, por meio da expulsão ou mesmo da execução. Também não se faz tão-somente em termos da equação de Leonardo como um inimigo, humano, de guerra. Não, o patamar da identificação de Leonardo nesse episódio é o de um mais que declarado inimigo mama'e, "espírito", extremamente poderoso e perigoso pelo poder incontrastável que detém: Leonardo é identificado no episódio em consideração com um indivíduo da espécie do terrível mama'e yaku’i ou yumi'ama'e, as "flautas sagradas", um indivíduo na casa de quem, aliás (conforme o item 5 da narrativa), as flautas devem ser executadas, mas são raivosamente rejeitadas. Note-se que em 1995 sugeri que a "casa das flautas" era, à época da chegada dos Kamayurá ao Alto Xingu (estimativamente, no século XVIII), a instituição de arregimentação de guerreiros, papel que ela desempenhou até o congelamento da guerra na re- 
gião, no século XX, com a pax xinguensis imposta exatamente pelos irmãos Villas Boas. Observe-se também que os mama’e em geral somente são controláveis pela política xamânica, monopolizada pelos paye, particularmente - entre os Kamayurá - monopolizado por seu paye de ver e ouvir, o próprio chefe (Menezes Bastos, 1984-1985, 2001).

Por fim, o terceiro aspecto que gostaria de realçar no episódio: a vingança dos Kamayurá foi violenta e inexorável, abatendo-se tanto sobre Leonardo quanto sobre Pele de Reclusa. Sobre Leonardo, devido ciúme, indiscrição, violência, irreciprocidade enfim. Leonardo teve de sair da aldeia kamayurá e perdeu a namorada que, roubada do chefe, queria somente para si. Perdeu-a violentada por todos - do excesso por extrema restrição, representado pelo egoísmo ou avareza amorosa, ao excesso por absoluta falta de limite, figurado pelo amor forçado de todos. Pele de Reclusa - a involuntária autora da violação original -, estuprada, foi expulsa da aldeia. ${ }^{18}$

É bom deixar claro que a vingança em tela não foi impulsionada por ciúme de Kutamapù, ou seja, ela não foi ocasionada por um desejo acumulador do chefe kamayurá, ele mesmo, em relação a Pele de Reclusa. Não, a vingança foi impulsionada pela rejeição radical de Kutamapù e dos Kamayurá em geral do ciúme - pois Leonardo queria Pele de Reclusa somente para si - e da violência, enfim da extrema irreciprocidade de todo o affair envolvendo Leonardo e Pele de Reclusa. Em relação a este terceiro ponto, vale observar que as punições a traidores e traidoras conjugais no mundo kamayurá não parecem alcançar dimensões maiores que as da simples rusga. $\mathrm{Na}$ grande maioria das vezes, elas se reduzem a pequenas surras do(a) traído(a) no(a) traidor(a) (diferença que os Kamayurá sempre fazem questão de salientar entre eles e os "civilizados”). Na mitologia, porém, essas punições costumam ter intensidade absolutamente dramática, quase sempre provocando catástrofes e rup- 
turas (“origens") 19 - tudo se passa, então, no episódio aqui narrado, como se ele tivesse pertinência mítica, ocasionando, como ocasionou, pelo menos duas importantes rupturas ou origens: o divórcio forçado de Kutamapù com o estupro e o ostracismo de Pele de Reclusa; e o afastamento - a inimizade mesmo - de Leonardo dos Kamayurá, com sua progressiva generalização no relativo aos Villas Boas como um todo (Menezes Bastos, 1989).

O que esse episódio terá a ver com meu objeto de atenção aqui? Por meio do estudo das "flautas sagradas" nas Terras Baixas da América do Sul, contribuir para a etnologia respectiva nos capítulos das relações de poder, da construção sociocultural dos sentidos e dos gêneros e, em geral, da constituição do mundo.

\section{As flautas sagradas kamayurá}

As "flautas sagradas" ou "rituais" kamayurá - em Kamayurá, yaku’i ou yumi'ama'e - são aerofones do tipo flauta com conduto e defletor. ${ }^{20}$ Medem em torno de um metro e têm quatro orifícios digitais (evidentemente, não as devo mostrar em foto, como inadvertidamente o fiz em meu texto de 1978[1999a]). Quase sempre, elas são tocadas em trio por um maraka’ùp, "mestre de música", e dois ajudantes ou aprendizes. Quando executadas em solo, o são sempre por um mestre, especialmente virtuoso. As yaku'i constituem o ego de um grupo de parentesco do tipo kindred (orientado em ego), chamado em Kamayurá yaku'iare’ùy ou yumiama'earèùy (ao pé da letra, algo como "semelhantes a yaku'i", "pessoal de yaku' ' vendo outros onze instrumentos musicais, conforme a figura a seguir: ${ }^{21}$ 


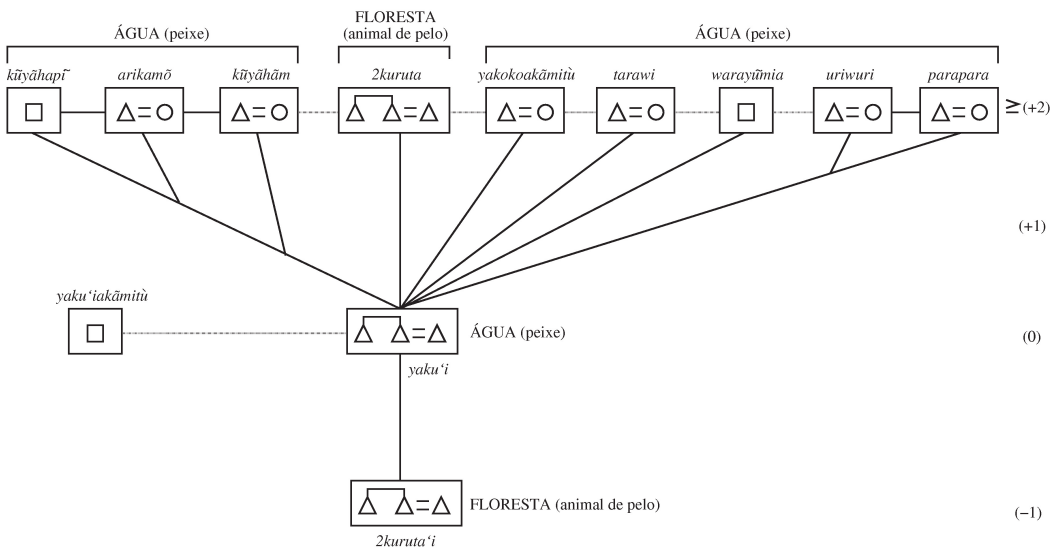

Figura 1: As "flautas sagradas" kamayurá e sua parentela

$\mathrm{Na}$ geração +2 da parentela em consideração, estão os aerofones do tipo trompete kuyahapi, arikamo e kuyaham (cujo meio é a água, sendo similares a "peixes"); ${ }^{22}$ as flautas kuruta (similarmente às yaku’i, também com conduto e defletor; seu meio é a floresta, e elas são semelhantes a "animais de pêlo"); os chocalhos globulares yakokoakamitù; os aerofones tipo clarinete tarawi; ${ }^{23}$ o trocano warayumia; e os zunidores uriwuri e parapara (os cinco últimos também são seres aquáticos, identificados com “peixes”). Na geração 0, a das yaku’i, localizam-se os chocalhos yaku'iakamitì do tipo em fieira e usados amarrados ao tornozelo direito dos dançarinos. O meio original desses dois instrumentos - como também o das flautas yaku'i - é também a água, sendo todos parecidos com “peixes”. Na geração -1, ficam as flautas kuruta’i, que, como as yaku’i e kuruta, têm conduto e defletor. Seu meio é a floresta e sua identificação é como "animal de pêlo". Note-se que - interessantemente - a esse kindred falta a geração $+1 .{ }^{24}$ Vale deixar bem claro: todos esses instrumentos têm o estatuto de mama'e. 
As flautas yaku'i encontram no tapìy seu espaço preferencial - mas não exclusivo - de guarda. Essa casa ocupa uma importante posição na aldeia kamayurá, uma aldeia que é, ela mesma, uma cosmografia: situada no centro da aldeia, a "casa das flautas" é um dos lugares originais por excelência de seu cosmo, nela se concentrando sua própria criação. Consistentemente com isso, ela é também chamada de hoka’ù, literalmente, "casa da água", e de hotatap, ao pé da letra, "casa do fogo". Simultaneamente, ela é o espaço por excelência da masculinidade entre os Kamayurá e xinguanos em geral, daí a sua outra tradução de "casa dos homens". Ali - conforme já referido -, as mulheres não podem entrar, sob pena de estupro coletivo.

A "casa das flautas" tem, na face que dá para oeste, duas portas (chamadas de apùy, "narinas"). Na oposta, somente uma. Lembro que, entre os Kamayurá, as relações sexuais são monitoradas, vigiadas pelo cheiro que elas mesmas emitem, assim como pelos odores que, isoladamente, os fluidos masculino e feminino (incluindo, crucialmente, o sangue menstrual) liberam. Sendo o tapùy o espaço nevrálgico da masculinidade entre esses índios, masculinidade esta politicamente manifestada pela capacidade de controle da sexualidade, através tipicamente de seus finos olores, nada de estupendo que essa casa seja, ela mesma, cosmograficamente, um grande nariz a tudo sensoriar - dir-se-ia algo não como um pan-ótico, mas "pan-osfrésico".

Nos depoimentos nativos, a casa das flautas aparece como uma das distinções básicas dos apùap, os "Kamayurá de verdade", chamados, exatamente, de tapùyatapiā ("os da aldeia que tem tapùy”). Aqui, o tapìy é uma grande construção onde se passam os ritos secretos da comunidade masculina, ligados às "flautas sagradas" e aos outros instrumentos que compóem seu kindred. Aqui também é onde se fazia antigamente a reclusão pubertária, então sempre coletiva (ver Menezes Bastos, 1995). 
Rafael José de Menezes Bastos. Leonardo, a flauta...

As yaku'i não podem ser vistas pelas mulheres, sua música, porém, é ouvida por elas de maneira extremamente diligente. ${ }^{25}$ Entre os Kamayurá, essa não é a única proibição visual - mas não auditiva às mulheres: o Payemeramaraka, "ritual da comunidade dos pajés", também não deve ser visto por elas (ver Menezes Bastos, 1984-1985). Adicionalmente a isso, vale recordar que presenciei um episódio na aldeia kamayurá em 1981 - ligado a uma caçada de porcos, depositados mortos no pátio da aldeia -, do qual elas também se isolaram visualmente, trancando-se em suas casas e fechando as portas, temerosas de que os homens se transformassem em mama'e. Enquanto isso, os homens discutiam dramaticamente no pátio da aldeia seu processo de xinguanização (Menezes Bastos, 1995). Tudo faz parecer, então, que as proibições visuais às mulheres, entre os Kamayurá, apontam para um dever seu (das mulheres), absolutamente essencial, de evitação do universo dos mama'e. Especificamente, elas têm como base o temor feminino, verdadeiro pavor, de que os homens se transformem em mama'e, assim vindo a dar fim ao mundo, sempre por um fio entre eles, do contrato social. ${ }^{26}$ Entre os Kamayurá, o controle humano dos mamáe somente é passível de ser feito através do xamanismo, monopólio masculino.

Quanto às "flautas sagradas", porém, observe-se que as mulheres não somente não devem vê-las: elas também não devem saber quem as toca. Note-se que os homens, quando as estão executando, encerram-se no tapìy - quando eles as tocam no pátio da aldeia, as portas das casas residenciais são fechadas, ali devendo ficar reclusas as mulheres e crianças. Observe-se por fim que, quando executando as yaku' $i$, os homens não devem tomar banho de imersão, mas de coité, não podem manter relações sexuais, sujeitando-se a mais uma série de outros interditos, tudo evocando o comportamento das mulheres quando menstruadas. Essa evocação me inspirou uma comparação das yaku'i com os instrumen- 
tos musicais similares do Alto Rio Negro (ver Hugh-Jones, 1979; Hill, 1993; e Piedade, 1997), os dois universos musicais apontando para uma menstruação simbólica dos homens - sinal de seu poder no plano não biológico, mas político -, o que recorda fatos em tudo por tudo semelhantes da Nova Guiné. ${ }^{27}$

As "flautas rituais" - e sua parentela - são temas muito presentes na mitologia kamayurá e xinguana em geral. Aponto abaixo, de maneira extremamente resumida, alguns de seus nexos mais importantes nessa mitologia: ${ }^{28}$

1) As flautas em comentário são ta’angap, "cópias", feitas com a madeira de determinadas árvores, de mamảe subaquáticos. Essas "cópias" foram produzidas por Ayanama, um dos demiurgos kamayurá. ${ }^{29}$

2) Era uma vez... essas flautas constituíam domínio exclusivo das mulheres. Então, havia uma completa inversão daquilo que hoje acontece: as mulheres pescavam, os homens trabalhavam a mandioca e cuidavam das crianças; às mulheres cabia com exclusividade a "casa das flautas", os homens sendo proibidos de ali entrarem. Nesse tempo - para sintetizar -, a constituição do mundo kamayurá, do ponto de vista daquilo tudo que se refere aos gêneros, era inversa daquela que hoje ele tem.

3) Insatisfeitos com isso, os homens fizeram uma revolução, tomando as flautas das mulheres e constituindo o mundo como hoje ele é. Para que essa revolução pudesse ser feita, Morenayat, "o dono do Morena”, outro demiurgo kamayurá, ameaçou as mulheres, executando os horrendos zunidores uriwuri e parapara. ${ }^{30}$ A partir de então, a constituição presente do mundo foi feita, sua manutenção estando assentada no medo, pavor, verdadeiro horror que as mulheres devotam ao universo das "flautas rituais" e dos mama'e em geral. Repito que somente os homens, entre os Kamayurá e xinguanos em geral, podem ser xamãs. 
Desde que iniciei meus estudos no Alto Xingu, tenho partido da idéia de que os sentidos, para longe de constituírem aparelhos biopsicológicos invariáveis, são - como o corpo para Marcel Mauss - os primeiríssimos objetos de construção cultural. Partindo desse princípio, elaborei a noção de audição do mundo (em inglês, no original, world hearing [Menezes Bastos, 1999b]) para dar conta de cosmologias ameríndias com um nítido primado no mundo da audição, diferentemente do que acontece no Ocidente, onde a visão é o sentido primordial. Os Kamayurá são um povo para o qual a noção de audição do mundo - muito mais que a de visão do mundo - cabe como uma luva: para eles, o verbo anup, cujo significado original é "ouvir", indica também o sentido de "compreender", tendo uma posição hierárquica superior àquela ocupada pelo verbo tsak, originalmente "ver", mas que também aponta para o nexo de "entender". Assim, pode-se dizer que, entre os Kamayurá, "ver” supõe uma forma analítica de percepção e conhecimento, do campo da intelecção e explicação. Note-se que a exacerbação da capacidade de "ver", entre eles, é tida como sinal de extrema associalidade, caso dos feiticeiros e, pior ainda, dos mama'e - entre os quais as flautas yaku'i e muitos dos componentes de sua parentela, especialmente as buzinas kuyahapi, arikamo e kuyaham, que não têm ouvidos e nariz, somente têm olhos e bocas - que devoram, não propriamente comem - ferozes. Em contraponto a isso, a noção de "ouvir" indica, para os índios em consideração, a percepção e o conhecimento sintéticos do domínio da sensibilidade e da compreensão; a capacidade exagerada de ouvir é considerada pelos Kamayurá como índice de virtuosidade nas artes da música e verbal.

Quando antes aqui falei que o episódio cuja narrativa deu começo a este texto tinha pertinência mítica, desejava apontar para o fato de que ele, para os Kamayurá - e para quem os procure compreender -, tinha natureza originante e modelar, encerrando catástrofes prototípicas ou, 
Revista de Antropologia, São Paulo, USP, 2006, v. 49 no 2.

exatamente, origens. Se, para os Kamayurá, então, o mito encontra sua vocação na ruptura, a história, em contraposição, a tem na continuidade. Tudo se passa, para os Kamayurá, como se o passado - o passado mesmo, o irrecuperavelmente perdido - somente existisse para o mito, para a história somente existindo presentes, mais ou menos presentificados pela indagação (Sousa, 1981). Como já apontei, o episódio em tela ocasionou duas grandes rupturas ou catástrofes, demarcando as origens:

1) do divórcio de Kutamapù com o ostracismo de Pele de Reclusa, dramaticamente intermediados pelo estupro coletivo dela;

2) e do afastamento de Leonardo dos Kamayurá, germe do afastamento cada vez mais definitivo dos irmãos Villas Boas como um todo em relação a esses índios. Note-se que a partir daí os Kamayurá - diferentemente dos Yawalapití - passaram a orientar seu contato com o mundo dos brancos para o "Destacamento Xingu", estabelecimento então mantido pela Força Aérea Brasileira acerca do Jacaré (ver Menezes Bastos, 2004a).

Kutamapù ordenou a colocação na casa de Leonardo do trio de yaku' $i$ tão-somente porque, enciumado com o affair que envolvia sua esposa, calculadamente esperava a reação vingativa dos homens em face da violação, por parte dela, da regra de proibição às mulheres da visão das "flautas sagradas". Mas essa interpretação do episódio - que o equacionaria como um mero crime passional - não faz o menor sentido para os Kamayurá e para quem quer que os procure compreender. Tudo começa pelo fato de que a reação do chefe ao affair responde ao caráter de irreciprocidade radical com que Leonardo estabeleceu suas relaçóes com Pele de Reclusa. Trata-se, enfim, de uma reação a um ato de guerra contra os Kamayurá. Mas não é só: essa interpretação sustenta-se na falsa idéia de que as flautas em tela são entes materiais, inertes, e não como realmente elas são seres dotados de pessoalidade, agência, de subjetividade enfim. Quando 
Pele de Reclusa violou o inviolável - alicerce da constituição do mundo kamayurá -, ela acionou o interruptor que desencadeou a seqüência de transformaçōes que aconteceram sob a ética feroz das "flautas sagradas", liberadas de controle humano: a de Leonardo em "flauta" - recusante de sua própria música -, a de sua casa na "casa das flautas" e, por fim, dos homens kamayurá numa coletividade delas.

\section{Notas}

1 A versão original deste texto, lida na mesa-redonda "Antropologia \& estética - a arte como gnósis e visão do mundo", na 25a Reunião Brasileira de Antropologia (Goiânia, 11-14/6/6), saiu com alterações em Antropologia em Primeira Mão, n. 85 (2006). Agradeço a Eduardo Diatahy Bezerra de Menezes, organizador da mesa, Ordep Serra e Idilva Germano, seus demais integrantes, pelos comentários. A versão seguinte foi apresentada no simpósio "Onda de choque: novas investigaçōes sobre as flautas rituais nas Terras Baixas da América do Sul”, no $52^{\circ}$ Congresso Internacional de Americanistas (Sevilha, 17-21/7/6). Agradeço, agora, a Jonathan Hill e a Jean-Pierre Chaumeil, organizadores do simpósio, e a seus outros membros. A presente versão é diferente das anteriores.

2 Na Universidade Federal de Santa Catarina, também coordena o Núcleo de Estudos Arte, Cultura e Sociedade na América Latina e Caribe (http://www.musa.ufsc.br); é pesquisador do $\mathrm{CNPq}$ (1B). E-mail: rafael@pesquisador.cnpq.br.

3 Conforme <http://www.bartleby.com/196/>, acessado em 6/6/2006. Tradução minha da epígrafe: "O outro grande tipo de magia por simpatia, que eu chamo de Magia por Contágio, procede com base na noção de que as coisas que uma vez estiveram juntas devem assim permanecer para sempre, mesmo quando bem separadas umas das outras, numa relação de simpatia tal que aquilo que ocorra com umas deve também acontecer com as outras. Então, a base lógica da Magia por Contágio, como aquela da Magia Homeopática, é uma associação errada de idéias; sua base física, se é que podemos falar disso aqui, como a base física da Magia Homeopática, é um meio material tal que, como o éter da física moderna, se supõe que conecte os objetos distantes e possa transmitir características de uns para os outros". 
4 Recordo que no sistema em comentário o número 421 corresponde aos "instrumentos (aerofones) com defletor ou flautas" (em inglês, edge [aerophones] instruments or flutes). Brevemente falando, esse sistema tem como nexos primeiros a discriminação entre os elementos (cordas, colunas de ar, membranas, etc.) responsáveis pela geração sonora nos instrumentos musicais e pelos processos que a geram (para cordas, por exemplo, dedilhar, percutir, tocar com arco etc). Como se pode ver, a dimensão timbrística - tão importante, aliás, para as músicas ameríndias, como o caso kamayurá tão bem ilustra - está na sua base.

5 No sistema em tela, idiofones são os instrumentos que têm no seu próprio ("idio") corpo o elemento responsável pela geração do som.

6 A proposta de Hill e Chaumeil (2006) para o simpósio referido na nota 1, os trabalhos nele lidos, inclusive o meu - a sair em livro organizado por Hill e Chaumeil -, coloca de maneira ao mesmo tempo detalhada e abrangente o interesse etnográfico do estudo das "flautas sagradas". Ver Piedade (2004) para uma investigação paradigmática sobre a questão, com base no observatório waurá (wauja), aruaque xinguanos. Ver também Barcelos Neto (2004) e Mello (2005).

7 As denúncias indígenas (suyá, kayabí, trumaí) contidas em Menezes Bastos (2004a) também têm essa característica. Note-se que a visão yawalapití dos Villas Boas é bem diferente daquela dos Kamayurá, sendo altamente positiva (conforme Menezes Bastos, 1989, 1990, 1995).

8 A presente transcrição é resumida e aprimora a tradução de 1989, feita por informantes bilíngües, incluindo o próprio Takumã.

9 "Xingu", no português dos Kamayurá, é a região chamada por eles, em kamayurá, de Yakarep ("Jacaré"), acerca do hoje Posto Indígena Diauarum.

10 Leonardo era o mais moço dos irmãos Villas Boas (Orlando, o mais velho). Leonardo faleceu em 1961 de problemas cardíacos, tendo sido dado seu nome ao antigo Posto Indígena Capitão Vasconcelos como reconhecimento da importância de sua contribuição para a criação do Parque.

11 O pai de Takumã era o então chefe e grande pajé Kutamapù. Nessa época, a aldeia kamayurá localizava-se na boca do Ribeirão Tuatuari, em território que os próprios Kamayurá reconhecem como yawalapití (ver Menezes Bastos, 1995).

12 A nota 72 do original de 1989 considera que Takumã aqui se queixa dos transtornos ocasionados ao perfeito cumprimento de seu período de reclusão pubertária por sua convivência com os Villas Boas. Explicitamente, ele expõe o choque entre 
os pontos de vista de seu pai e os de Leonardo, e os dos Villas Boas em geral, quanto à duração do mesmo. O primeiro - que buscava formar Takumã, seu primogênito, como chefe - o queria longo, o segundo condicionando-o a ser curto. Se, no português kamayurá de contato no contexto da presente narrativa, "dez anos" aponta para uma duração longa, "dois meses" o faz para uma muito breve. Note-se que a maior ou menor duração da reclusão pubertária aponta o maior ou menor cuidado do pai na formação de seu filho, o que é especialmente importante no caso da formação do chefe.

13 Esses outros caraíbas eram os demais funcionários da Expedição Roncador-Xingu que acompanhavam os Villas Boas à região dos formadores do Xingu.

14 Transcrevo ipsis litteris a nota 73 do original de 1989: "A expressão 'errar caminho', com toda a piedade que a caracteriza, é usada pelo narrador de maneira altamente sutil e eficaz no sentido da condenação moral de Leonardo do ponto de vista do próprio quadro de valores retóricos administrado por esse herói em sua pedagogia de contato interétnico. No sentido da condenação e, caritativamente, do perdão"!

15 Manga’uhet: "imediatamente ex-reclusa pubertária”. Kutamapù, pai de Takumã, tinha três esposas então, Pele de Reclusa sendo a mais jovem.

16 Yumiama’e (ou yaku'i) são as "flautas sagradas" kamayurá (ver adiante).

17 "Falar mal" (yéeng nikatuite), algo como "xingar", comportamento verbal associal, característico do feiticeiro e contrário por excelência à etiqueta xinguana.

18 Ela mudou-se desde então para a Ilha do Bananal, onde se casou com um eminente chefe karajá.

19 Recordo-me aqui imediatamente dos mitos de origem do ritual do Yawari (Menezes Bastos \& Hermenegildo, 2002, p. 140; Menezes Bastos, 2004b, p. 96) e do pequi (Agostinho, 1974a, p. 109-12), entre tantos outros.

20 Conforme meu texto de 1978[1999a]. Ver Piedade (2004) para um estudo, como já disse, paradigmático das flautas em comentário entre os xinguanos aruaque Wauja. Vale referir - como os xinguanos não são simplesmente iguais (nem simplesmente diferentes, como apontei uma vez) - que, entre os Kamayurá, as flautas em consideração não são máscaras, como é o caso entre os Wauja, segundo o citado texto de Piedade, como também os - também magníficos - de Barcelos Neto (2004) e Mello (2005).

21 Conforme figura que está em meu texto de 1978 (ver 1999a, p. 228). 
22 Nesse tipo de aerofone, o som tem origem na vibração, por pressão de ar, dos lábios do tocador.

23 No caso dos clarinetes, o som tem origem numa palheta, posta a vibrar pelo ar emitido pelo tocador. Essas diferenças acústicas - envolvendo flautas, trompetes e clarinetes, assim como os demais instrumentos - são de extremo interesse para os índios kamayurá e, em geral, das Terras Baixas como um todo.

24 Essa omissão talvez aponte para o nexo de que somente interessa ao referido kindred os ancestrais (geraçôes +2 e superiores), a prole $(+1)$ e os siblings de ego (e ego, é claro), devendo-se notar que no pensamento kamayurá a autoria - sua, por assim dizer, assinatura - da substância genealógica é dos ancestrais, sendo apenas transmitida, veiculada pela geração +1 .

25 Conforme Mello (2005), para um estudo aprofundado sobre essa temática entre os Wauja, que envolve, de um lado, a música das "flautas sagradas" masculinas e, de outro, parte relevante do repertório da música vocal feminina. Segundo esse estudo, as mulheres ouvem as flautas para gravarem suas melodias, transpondo-as - ou melhor, tomando-as como modelos -; então, para sua música vocal, particularmente aquela do ritual do Iamurikumã.

26 Recordo que o mito que está na base do ritual do Iamurikumã apresenta este, por assim dizer, risco em estado original - o da transformação dos homens em mama'e, provocando o mesmo entre as mulheres e, então, o fim da socialidade (ver Mello, 2005). Tratei da fragilidade do contrato social humano entre os Kamayurá em alguns trabalhos, entre os quais os de 1990, 1993, 1995 e 2004b. Sobre o xamanismo, conforme meu texto de 1984-1985.

27 Conforme Hogbin (1970), entre tantos autores. A comparação referida está em Menezes Bastos (1999a[1978], pp. 223-32). Ver Piedade (2004) e alguns dos textos presentes em Gregor e Tuzin (2001) para retomadas recentes da questão.

28 Para coletâneas da mitologia em tela, conforme o já referido Agostinho (1974a), Agostinho (1974b, pp. 159-201) e Villas Boas (1975). Agostinho (1974a, pp. 113-27) recolhe algumas narrativas especificamente sobre as ditas flautas e sua parentela.

29 A noção de ta'angap é extremamente rica e complexa, tanto quanto a de mimese. Tratei dela em vários textos, entre os quais os de 1984-1985, 1990 e 2001.

30 Morena é a região onde o mundo se originou segundo os Kamayurá. Ela se encontra acerca do Yakarep. 
31 Acessível também on-line em <www.musa.ufsc.br>.

32 Este livro tem uma segunda edição, de 1999, feita em Florianópolis pela Editora da Universidade Federal de Santa Catarina. Recordo que ele transcreve, de maneira praticamente ipsis litteris, minha dissertação de mestrado, defendida em 1976 na Universidade de Brasília.

33 Disponível também on-line em www.antropologia.ufsc.br.

34 Idem.

35 Disponível também em <www.musa.ufsc.br>.

36 Idem.

\section{Bibliografia}

AGOSTINHO, Pedro

1974a Mitos e outras narrativas kamayurá, Bahia, Universidade Federal da Bahia.

1974b Kwarì: mito e ritual no Alto Xingu, São Paulo, EPU/Edusp.

BARCELOS NETO, Aristóteles

2004 Apapaatai: rituais de máscaras no Alto Xingu, São Paulo, Universidade de São Paulo, tese de doutorado em Antropologia Social.

GREGOR, Thomas A. \& TUZIN, Donald (eds.)

2001

Gender in Amazônia and Melanesia: An Exploration of the Comparative Method, Berkeley/Los Angeles/London, University of California Press.

HILL, Jonathan

Keepers of the Sacred Chants: The Poetics of Ritual Power in an Amazonian Society, Tucson, University of Arizona Press.

HILL, J. \& CHAUMEIL, Jean-Pierre

2006

"Burst of Breath: New Research on Indigenous Ritual Flutes in Lowland South America", Symposium Proposal to the 52nd ICA.

HOGBIN, H. Ian

The Island of Menstruating Men: Religion in Wogeo, New Guinea, Scranton, Chandler Publishing Company. 
HORNBOSTEL, E. M. \& SACHS, Curt

1961[1914] "Classification of Musical Instruments" (English Version), Galpin Society Journal, 14: 3-29.

HUGH-JONES, Stephen

1979 The Palm and the Pleiades: Initiation and Cosmology in Northwest Amazonia, Cambridge/New York, Cambridge University Press.

MELLO, Maria Ignez Cruz

2005 Iamurikuma: música, mito e ritual entre os Wauja do Alto Xingu, Florianópolis, Universidade Federal de Santa Catarina, tese de doutorado em Antropologia Social. ${ }^{31}$

MENEZES BASTOS, Rafael José de

1984-1985 "O 'Payemeramaraka’ kamayurá - uma contribuição à etnografia do xamanismo no Alto Xingu", Revista de Antropologia, vol. 27/28: 139-77.

1989 "Exegeses yawalapití e kamayurá da criação do Parque Indígena do Xingu e a invenção da saga dos irmãos Villas Boas", Revista de Antropologia, vol. 30/31/ 32: 391-426 (1987/88/89).

1990 A Festa da Jaguatirica: uma partitura crítico-interpretativa, São Paulo, Universidade de São Paulo, tese de doutorado em Antropologia Social.

1993 "A saga do 'Yawari': mito, música e história no Alto Xingu", in VIVEIROS DE CASTRO, E. \& CARNEIRO DA CUNHA, M. (orgs.), Amazônia: etnologia e história indigena, São Paulo, Universidade de São Paulo, pp. 117-46.

1995 "Indagação sobre os Kamayurá, o Alto Xingu e outros nomes e coisas: uma etnologia da sociedade xinguara, Anuário Antropológico/1994, pp. 227-69.

1999a[1978] A musicológica kamayurá: para uma antropologia da comunicação no Alto Xingu, Brasília, Funai. ${ }^{32}$

$1999 b$ "Apùap World Hearing: On the Kamayurá Phono-Auditory System and the Anthropological Concept of Culture", The World of Music, vol. 41(1): 85-96.

2001 "Ritual, história e política no Alto Xingu: observaçōes a partir dos Kamayurá e do estudo da Festa da Jaguatirica (Jawari)", in FRANCHETTO, B. \& HECKENBERGER, M. (orgs.) Os povos do Alto Xingu: história e cultura, Rio de Janeiro, Editora da UFRJ, pp. 335-57.

2004a “Cargo anti-cult' no Alto Xingu: consciência política e legítima defesa étnica”, Antropologia em Primeira Mão, $71 .{ }^{33}$ 
Rafael José de Menezes Bastos. Leonardo, a flauta...

2004b "The Yawari Ritual of the Kamayurá: A Xinguano Epic", in KUSS, Malena (ed.), Music in Latin America and the Caribbean: An Encyclopedic History. Volume 1: Performing Beliefs: Indigenous Cultures of South America, Central America and Mexico, Austin, University of Texas Press, pp. 77-99.

MENEZES BASTOS, Rafael José de \& HERMENEGILDO, José de

2002 "A Festa da Jaguatirica: Primeiro e Sétimo Cantos. Introdução, transcrição e comentários", Ilha: Revista de Antropologia, vol. 4(2): 133-74. ${ }^{34}$

PIEDADE, Acácio Tadeu de Camargo

1997

Música Yepamasa: por uma antropologia da música no Alto Rio Negro, Florianópolis, Universidade Federal de Santa Catarina, dissertação de mestrado em Antropologia Social. ${ }^{35}$

2004 Canto do Kawoká: música, cosmologia e filosofia entre os Wauja do Alto Xingu, Florianópolis, Universidade Federal de Santa Catarina, tese de doutorado em Antropologia Social. ${ }^{36}$

SOUSA, Eudoro de

1981

História e mito, Brasília, Editora da Universidade de Brasília.

VILLAS BOAS, Orlando \& VILLAS BOAS, Cláudio

1975 Xingu: os indios, seus mitos, 2.ed., São Paulo, Edibolso. 
ABSTRACT: The article contributes to the anthropology of the sacred flutes in lowland South America by retaking the analysis of an episode that occurred between 1947 and 1953 involving Leonardo Villas Boas and the Kamayurá, a Xinguano Tupian-Guarani speaking society. At that time, Leonardo - the youngest of the Villas Boas Brothers - had an ongoing and public love affair with Skin of Secluded, one of the wives of the great shaman and chief, Kutamapù. The affair caused a commotion among the Indians, who placed a trio of sacred yaqu'i flutes inside Leonardo's house. From that moment on, every time Skin of Secluded went there, she would see the flutes. As she broke the rule that dictates that women are prohibited of seeing the flutes, Skin of Secluded was collectively raped. This originated her ostracism and the Villas Boas Brothers' unfriendly relations with the Kamayurá. For the Kamayurá, "seeing" contrasts with "hearing"; the former pointing to an analytical form of knowledge ("explanation"), and the latter to a synthetic one ("comprehension"). The Kamayurá interpret strengthening of the capacity of "seeing" as a signal of anti-sociality, as in the case of the witches, or of supreme sociality, as in the case of the shamans. In contrast, the strengthening of the aptitude of "hearing" is considered a signal of virtuosity in music and verbal art. Among the Kamayurá, women are forbidden to see the sacred yaqu'i flutes, yet they are expected to hear them. The clues for an indigenous interpretation of the episode arise from their construction of the senses, genders and power - in short, from their ways of constituting the world: once Skin of Secluded violated the inviolable, Leonardo was transformed into a "flute", his house into the "flutes' house", and the Kamayurá men into a collectivity of flutes. As a result of this, everything started to happen under the flutes' ferocious ethics.

KEY-WORDS: sacred flutes, Upper Xingu, Kamayurá Indians, cosmology, world hearing. 